\title{
CORRESPONDENCE
}

\section{Psychotropic medication: resistance, adherence and religious objections}

Mitchell \& Selmes (2007) neglect a key reference that is useful in developing our understanding of this issue. Pound et al (2005) conducted the qualitative equivalent of a meta-analysis of issues surrounding the way in which patients take (or don't take) their medication as prescribed. Out of this was identified the concept of 'resistance' to taking medication. This is a significant conceptual and practical theme. It has particular importance as it links the issue of taking psychotropic medication with taking medication in general. Resistance emphasises how taking medication interacts with a patient's sense of self and how not taking medication needs to be understood in this context.

Mitchell, A. J. \& Selmes, T. (2007) Why don't patients take their medicine? Reasons and solutions in psychiatry. Advances in Psychiatric Treatment, 13, 336-346.

Pound, P., Britten, N., Yardley, L., et al (2005) Resisting medicines: a synthesis of qualitative studies of medicine taking. Social Science and Medicine, 61, 133-155.

Daniel M. Beales Specialist Registrar in Forensic Psychotherapy, Edenfield Centre, Bolton, Salford \& Trafford Mental Health NHS Trust, UK (email Daniel.Beales@bstmht.nhs.uk)

doi: 10.1192 /apt.14.1.78

I am responsible for the care of patients on a psychiatric intensive care unit. All of our patients are detained under the Mental Health Act and many do not have capacity to consent to treatment. In my experience the most common causes for relapse are a combination of non-adherence or partial adherence to medication regimens and substance misuse.

'Compliance therapy' is a combination of cognitivebehavioural techniques, motivational interviewing techniques and psychoeducation, and it aims to promote a good therapeutic alliance between doctor and patient, with open discussion about the risks and benefits of medication. The therapy has been used with success in patients with psychosis and it reduces readmission rates and improves insight and adherence to medication (Kemp et al, 1996, 1998).

Relapse prevention is as important as treating the acute illness. Non-adherence to medication is an important risk factor that needs close monitoring. It is our responsibility as clinicians to ensure that our patients understand their illness, the need for treatment and the importance of engagement with the services. It is essential that this is in the context of a partnership between doctor and patient.
Kemp, R., Hayward, P., Applewhaite, G., et al (1996) Compliance therapy in psychotic patients: randomised controlled trial. $B M J, 312,345-349$.

Kemp, R., Kirov, G., Everitt, B., et al (1998) Randomised controlled trial of compliance therapy. 18-month follow-up. British Journal of Psychiatry, 172, 413-419.

Marlene M. Kelbrick Staff Grade Psychiatrist (email: mkelbrick@standrews.co.uk)

doi: 10.1192/apt.14.1.78a

Resolving non-adherence to pharmacotherapy should involve a comprehensive assessment of the patient's social circumstances and cultural and religious beliefs (Sattar et al, 2004). There is evidence that patients with strong spiritual values cope better with mental illness and have better insight into their condition. Such factors have a direct impact on treatment adherence and engagement in therapy (Kirov et al, 1998).

Religious laws do not restrict the use of psychotropic medications but many forbid the use of animal-based derivatives, specifically gelatinous products and stearic acid. These are generally derived from beef and/or pork products. This has major implications for many patients, particularly the followers of Judaism, Islam, Hinduism, Buddhism, Seventh Day Adventism and the Christian Orthodox Church (Sattar et al, 2004). There are also over four million vegetarians in the UK (Food Standards Agency, 2005).

Initial findings from a postal survey that we conducted locally suggest that many psychiatrists have remained ambivalent about discussing this subject with their patients, for fear of reducing adherence to psychotropic medication, and also that many are unaware of the presence of 'forbidden contents' in psychotropic medication.

We believe that, in order to instil a spirit of trust in our patients and improve medication adherence, psychiatrists should have a basic familiarity with religious dietary restrictions. Information on the gelatin or stearic acid content of medications can be obtained from the physicians' desk reference or electronic databases such as www.PDR.net or www. rxlist.com.

Food Standards Agency (2005) Consumer Attitudes to Food Standards Wave 5: UK Report. FSA.

General Medical Council (1998) Seeking Patient's Consent: The Ethical Considerations. GMC.

Kirov, G., Kemp, R., Kirov, K., et al (1998) Religious faith after psychotic illness. Psychopathology, 31, 234-235.

Mitchell, A. J. \& Selmes, T. (2007) Why don't patients take their medicine? Reasons and solutions in psychiatry. Advances in Psychiatric Treatment, 13, 336-346.

Sattar, S. P., Ahmed, M. S., Madison, J., et al (2004) Patient and physician attitudes to using medications with religiously forbidden ingredients. Annals of Pharmacotherapy, 38, 1830-1835. 
Waqqas A. Khokhar Specialty Registrar, North Trent Rotational Training Scheme in Psychiatry, Sheffield, UK (email: waqqaskhokhar@doctors.org.uk); Mohammed M. Ali North Trent Rotational Training Scheme in Psychiatry, Sheffield; Imran Hameed North Trent Rotational Training Scheme in Psychiatry, Sheffield; Javaria Sadiq Mayo Hospital, Lahore, Pakistan doi: 10.1192 /apt.14.1.78b

\section{Authors' reply}

We agree with Beales that Pound et al (2005) is a valuable and comprehensive review. We have cited this article elsewhere (Mitchell, 2006, 2007). It highlights widespread and understandable caution about taking medication and brings to light 'the lay practice of testing medicines, mainly for adverse effects'. We recommend this paper for further reading.

We also agree with Kelbrick that it is important to have a good therapeutic relationship with detained patients. This area was underemphasised in our article. Owing to space restrictions we did not review compliance therapy in detail but good reviews are available elsewhere (McDonald et al, 2002; McIntosh et al, 2006; Nadeem et al, 2006).

Khokhar \& Ali helpfully discuss cultural factors. We recently conducted a study on ethnic differences regarding treatment preferences (rather than adherence) in a cancer setting (Roy et al, 2005). More Asian than 'Caucasian' patients wanted to receive critical information from their GP rather than a hospital doctor. This was linked with their level of distress. More Asian patients received 'bad news' alone. We are currently trying to find out whether this has an effect on illness outcomes.

McDonald, H. P., Garg, A. X. \& Haynes, B. (2002) Interventions to enhance patient adherence to medication prescriptions. JAMA, 288, 2868-2879.

McIntosh, A. M., Conlon, L., Lawrie, S. M., et al (2006) Compliance therapy for schizophrenia. Cochrane Database of Systematic Reviews, issue 3. Art. no. CD003442

Mitchell, A. J. (2006) High medication discontinuation rates in psychiatry - how often is it understandable? Journal of Clinical Psychopharmacology, 26, 109-112.

Mitchell, A. J. (2007) Hypothesis: adherence behaviour with psychotropic medication is a form of self-medication. Medical Hypothesis, 68, 12-21.

Nadeem, Z., McIntosh, A. \& Lawrie, S. (2006) Schizophrenia: adherence to antipsychotics. BMJ Clinical Evidence, http:// clinicalevidence.bmj.com/ceweb/conditions/meh/meh.jsp (and follow link to Compliance therapy).

Roy, R., Symonds, R. P., Kumar, D. M., et al (2005) The use of denial in an ethnically diverse British cancer population. A cross-sectional study. British Journal of Cancer, 92, 1393-1397.

Alex J. Mitchell Consultant Liaison Psychiatrist, University of Leicester, UK (email: ajm80@le.ac.uk); Thomas Selmes Senior House Officer, York psychiatry scheme, UK

doi: 10.1192/apt.14.1.79

\section{Treatment of the victims of trauma}

Adshead \& Ferris (2007) emphasise how cognitivebehavioural approaches have become established as the core to treatment and quote recent National Institute for Health and Clinical Excellence (NICE) guidelines to support this (National Collaborating Centre for Mental Health, 2005). They are also clear that there are other models available for complex presentations of trauma-related pathology. It is unfortunate that NICE guidelines do not address the issues of the significant proportion of patients who discontinue treatment (which can average over $20 \%$ ) or fail to respond. Cognitive-behavioural approaches continue to develop, with metacognitive therapy in particular seeking to address these issues (Wells \& Sembi, 2004).

The development of cognitive-behavioural approaches that are primarily based not on exposure but on addressing individuals' difficulties in processing their response to trauma suggests the possibility of a rapprochement between different theoretical and therapeutic models. This would inform steppedcare approaches (Bower \& Gilbody, 2005) supporting appropriate matching of patient need and problem complexity with services and intervention.

Adshead, G. \& Ferris, S. (2007) Treatment of victims of trauma. Advances in Psychiatric Treatment, 13, 358-368.

Bower, P. \& Gilbody, S. (2005) Stepped care in psychological therapies: access, effectiveness and efficiency. British Journal of Psychiatry, 186, 11-17.

National Collaborating Centre for Mental Health (2005) PostTraumatic Stress Disorder: The Management of PTSD in Adults and Children in Primary and Secondary Care. National Clinical Practice Guideline Number 26. National Institute for Health and Clinical Excellence.

Wells, A. \& Sembi, S. (2004) Metacognitive therapy for PTSD. A core treatment manual. Cognitive and Behavioral Practice, 11, 365-377.

Daniel M. Beales Specialist Registrar in Forensic Psychotherapy, Edenfield Centre, Bolton, Salford, Trafford Mental Health NHS Trust, UK (email: Daniel.Beales@bstmht.nhs.uk)

doi: 10.1192/apt.14.1.79a

\section{Integrated community mental health teams for older adults: 20 years' experience}

An innovation in the Welsh county of Cardiff and Eastern Vale of Glamorgan is the establishment of community mental health teams (CMHTs) for older adults which are fully integrated with social services. The teams (which have existed since 1989) are led by social services, unlike the more recent partnership trusts in other regions where social workers are 'seconded' into health trusts.

With an endorsement from the Department of Health's recently outlined National Dementia Strategy (Department of Health, 2007), joint health and social care CMHTs for older adults could become the norm.

There are likely to be initial teething problems in establishing these teams, with a perceived clash of cultures. In Cardiff, examples of reconciliation on the 